\title{
PERANCANGAN SISTEM INFORMASI PENJAMINAN MUTU PERGURUAN TINGGI BIDANG SUMBER DAYA MANUSIA
}

\author{
Yeni Nuraeni \\ Program Studi Teknik Informatika, Universitas Paramadina, Jalan Gatot Subroto Kav. 97, Mampang, \\ 12790, Jakarta, Indonesia \\ E-mail: yeninur@hotmail.com
}

\begin{abstract}
Abstrak
Sumber daya manusia (SDM) di lingkungan perguruan tinggi yang terdiri dari dosen dan tenaga penunjang memiliki posisi yang sangat strategis, karena memiliki pengaruh langsung terhadap proses belajar, mutu lulusan dan pola keluaran yang kompetitif. Efektivitas kinerja dalam proses belajar mengajar dan perbaikan atmosfer akademik sangat dipengaruhi oleh standardisasi mutu yang ingin dicapai serta proses penjaminan mutu yang harus dilakukan oleh sebuah perguruan tinggi salah satunya dalam bidang sumber daya manusia (SDM). Syarat yang harus dipenuhi agar penerapan sistem penjaminan mutu SDM di sebuah perguruan tinggi dapat dilaksanakan dengan baik adalah ketersediaan basis data akurat yang dapat digunakan pada setiap pengambilan keputusan. Untuk itu perlu dikembangkan sistem informasi penjaminan mutu SDM di lingkungan perguruan tinggi. Sistem informasi penjaminan mutu SDM ini dapat berfungsi untuk memudahkan bagi perguruan tinggi dalam menjalankan penjaminan mutu, sehingga proses penjaminan mutu bisa dijalankan melalui tahap-tahap yang terangkai dan didukung oleh pangkalan data (basis data), sistem informasi manajemen, dan sistem pendukung keputusan yang terintegrasi. Adapun tahapan yang dilakukan dalam perancangan sistem informasi ini meliputi analisis kebutuhan, perancangan model proses, analisis kebutuhan perangkat lunak, dan desain.
\end{abstract}

Kata kunci: sistem informasi, penjaminan mutu perguruan tinggi, sumber daya manusia

\begin{abstract}
Human resources (HR) in the college environment consisting of lecturers and support staff have a very strategic position, because it has a direct impact on the learning process, the quality of graduates and the competitive output pattern. Effectiveness of performance in teaching and learning and improved academic atmosphere is strongly influenced by the standardization of quality to be achieved and the quality assurance process that should be done by a university either in the field of human resources (HR). Condition that must be met in order for the application of quality assurance system in a college human resources can be successfully implemented is the availability of accurate database that can be used in any decision-making. It is necessary to develop human resources information system of quality assurance in higher education environments. Human resource quality assurance information system can serve to make it easier for universities in implementing quality assurance, so that the quality assurance process can be run through the connected stages and supported by the data base (database), management information systems, and integrated decision support system. The stage that is done in designing information systems include requirements analysis, design process models, software requirements analysis, and design.
\end{abstract}

Keywords: information systems, higher education quality assurance, human resources

\section{Pendahuluan}

Suatu perguruan tinggi harus merumuskan standar tenaga kependidikan atau standar sumber daya manusia (SDM), di mana standar tersebut harus ditingkatkan secara terus menerus dari waktu ke waktu sehingga standar tersebut berkembang secara berkelanjutan (continuous improvement). Semakin tinggi standar SDM yang ditetapkan, semakin bermutu kondisi dosen dan tenaga penunjangnya.Standar ini merupakan acuan keunggulan mutu sumber daya manusia, serta bagaimana seharusnya sebuah program studi di suatu perguruan tinggi memperoleh dan mendayagunakan sumber daya manusia yang bermutu tinggi serta dapat memberikan layanan prima kepada sumber daya manusianya untuk mewujudkan visi, melaksanakan dan menyelenggarakan misi, dan mencapai tujuan yang dicita-citakan. Sumber daya manusia di 
sebuah program studi sarjana adalah terdiri dari dosen dan tenaga penunjangnya yang mencakup pustakawan, laboran, teknisi, dan tenaga kependidikan lainnya yang bertanggung jawab atas pencapaian sasaran mutu keseluruhan program tri darma perguruan tinggi.

Dosen adalah komponen sumber daya utama yang merupakan pendidik profesional dan ilmuwan dengan tugas pokok dan fungsi mengakuisisi, mentransformasikan, mengembangkan, menyebarluaskan, serta menerapkan ilmu pengetahuan, teknologi dan seni melalui pendidikan, penelitian, dan pelayanan/pengabdian kepada masyarakat. Dosen sebagai penentu mutu penyelenggaraan akademik, peningkatan mutu dosen harus direncanakan dan dilaksanakan selaras dengan kebutuhan, sehingga dapat mewujudkan visi, menyelenggarakan misi, dan mencapai tujuan yang telah ditetapkan.

Sebuah perguruan tinggi harus memiliki sistem pengelolaan mutu SDM yang memadai untuk pembinaan dan peningkatan mutu tenaga kependidikan, baik bagi dosen, pustakawan, laboran, teknisi, staf administrasi, dan tenaga kependidikan lainnya. Program studi sarjana yang baik harus memiliki tenaga kependidikan dengan jumlah, kualifikasi dan mutu kinerja yang sesuai dengan kebutuhan penyelenggaraan programprogram yang ada di program studi sarjana yang bersangkutan.

Untuk itu Direktorat Quality Assurance (QA) Universitas X sejak tahun 2008 melaksanakan assesment terhadap setiap program studi dengan tujuan membantu mewujudkan sistem pendidikan sehingga memiliki suasana akademik yang kondusif serta dapat mewujudkan sasaran yang ingin dicapai yaitu menjadi World Class University.

Akan tetapi saat ini penjaminan mutu yang dilakukan belum menyentuh seluruh aspek salah satunya bidang SDM belum dilakukan penjaminan mutu secara menyeluruh. Sampai saat ini, pelaksanaan penjaminan mutu masih terbatas pada penjaminan mutu yang berhubungan langsung dengan mekanisme proses belajar mengajar, belum menyentuh butir-butir mutu yang lainnya. Kendala yang dihadapi adalah kurangnya sosialisasi dan informasi mengenai mekanisme penjaminan mutu yang diinginkan oleh Universitas X karena terbatasnya SDM yang ada.

Dikarenakan terdapat kendala-kendala di atas maka dirasakan implementasi penjaminan mutu khususnya bidang SDM di lingkungan internal Universitas X belum dapat dilaksanakan secara optimal. Untuk mengatasi kendala-kendala tersebut, diperlukan upaya strategis dan berkelanjutan di antaranya dengan mengembangkan perangkat lunak sistem penjaminan mutu SDM yang dapat dijadikan sarana untuk menjamin implementasi penjaminan mutu SDM internal dan eksternal di Universitas X dapat dilakukan secara konsisten dan berkelanjutan.

Berdasarkan identifikasi terhadap masalahmasalah tersebut di atas, perlu dikembangkan suatu sistem informasi penjaminan mutu bidang sumber daya manusia dengan dua tujuan. Tujuan yang pertama yaitu proses penjaminan mutu bidang SDM akan menjadi tanggung jawab semua anggota komunitas di Universitas X, bukan hanya dilakukan oleh kelompok tertentu saja, karena proses pengisian data pada perangkat lunak penjaminan mutu tersebut melibatkan secara langsung semua anggota komunitas di X sesuai dengan fungsi, kedudukan dan jabatannya. Demikian pula perangkat lunak tersebut bisa digunakan sebagai alat monitoring mutu SDM yang sudah dicapai oleh setiap komunitas di lingkungan Universitas $\mathrm{X}$ sesuai dengan kewenangannya masing-masing. Tujuan yang kedua dapat memudahkan proses akreditasi yang dilakukan oleh BAN-PT maupun evaluasi diri EPSBED oleh Ditjen Dikti, karena semua data dan bukti aktivitas SDM yang menjadi standar nasional tersebut sudah terekam dalam basis data

Komponen sumber daya manusia di perguruan tinggi. Secara skematis, tenaga kependidikan atau sumber daya manusia di lingkungan perguruan tinggi dapat dilihat pada gambar 1 .

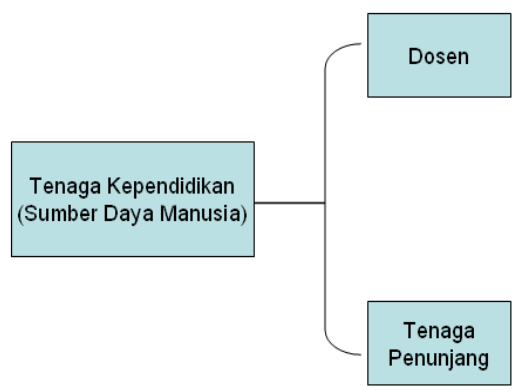

Gambar 1. Komponen SDM di lingkungan perguruan tinggi.

Adapun mengenai tugas masing-masing disebut secara berturut-turut di dalam Pasal 39 ayat (1) dan (2) UU Sisdiknas. Pasal 39 ayat (1) berisi pendidik bertugas merencanakan dan melaksanakan: proses pembelajaran, menilai hasil pembelajaran, melakukan pembimbingan dan pelatihan, melakukan penelitian dan pengabdian kepada masyarakat. Pasal 39 ayat (2) berisi tenaga kependidikan/penunjang bertugas melaksanakan: 
administrasi, pengelolaan, pengembangan, pengawasan dan pelayanan teknis untuk menunjang proses pendidikan pada satuan pendidikan

Mekanisme penetapan standar mutu SDM di perguruan tinggi. Standar ditetapkan dengan meramu visi program studi dan kebutuhan stakeholders. Oleh karena itu perlu dilakukan perumusan visi suatu program studi dan perumusan kebutuhan stakeholders dari program studi tersebut sebelum dilakukan penetapan standar SDM.

Sebelum merumuskan visi perlu diketahui terlebih dahulu tentang kekuatan, kelemahan, kesempatan dan ancaman program studi melalui analisis SWOT. Analisis SWOT akan membantu program studi dalam mengenali kekuatan atau kelemahan yang mungkin ada di dalam (internal) juga kesempatan/peluang atau ancaman yang mungkin ada di luar (eksternal) program studi. Visi program studi itu kemudian dijabarkan lebih lanjut menjadi serangkaian standar penyelenggaraan program studi. Salah satu rangkaian standar adalah standar keberhasilan penugasan kepada dosen dan tenaga penunjang sebagai salah satu butir mutu di dalam penjaminan mutu perguruan tinggi.

Dalam melakukan penjaminan mutu, selain visi terdapat juga satu hal yang selalu menjadi acuan, yaitu kebutuhan stakeholders, terutama tentang kualitas lulusan agar memenuhi kompetensi yang diperlukan oleh pengguna lulusan. Stakeholders tersebut dapat mencakup berbagai komponen, antara lain sektor produktif, masyarakat luas, pemerintah, dan masyarakat perguruan tinggi itu sendiri. Khusus dalam konteks penugasan kepada dosen dan tenaga penunjang (SDM), relevansi kompetensi lulusan dengan kebutuhan stakeholders sangat signifikan.

Kompetensi relevan yang dibutuhkan stakeholders dipengaruhi oleh penugasan kepada dosen dan tenaga penunjang. Di masa depan, kelulusan bukan semata-mata merupakan peristiwa pencapaian jumlah sks dan indeks prestasi, melainkan lebih dari itu yaitu pemenuhan mutu kompetensi yang dibutuhkan stakeholders. Mekanisme penetapan standar SDM dilingkungan perguruan tinggi dapat dilihat pada gambar 2 .

\section{Metodologi}

Metode pembangunan perangkat lunak sistem penjaminan mutu bidang SDM dalam penelitian ini menggunakan metode sekuensial linier yang terdiri dari tahapan analisis kebutuhan, perancangan model proses penjaminan mutu internal dan eksternal, analisis kebutuhan perangkat lunak dan tahapan desain. Pada tahapan analisis kebutuhan dilakukan studi pustaka dan analisis mengenai kebijakan, prosedur, standar mutu yang digunakan, kelembagaan dan organisasi pelaksana penjaminan mutu di Universitas Paramadina.

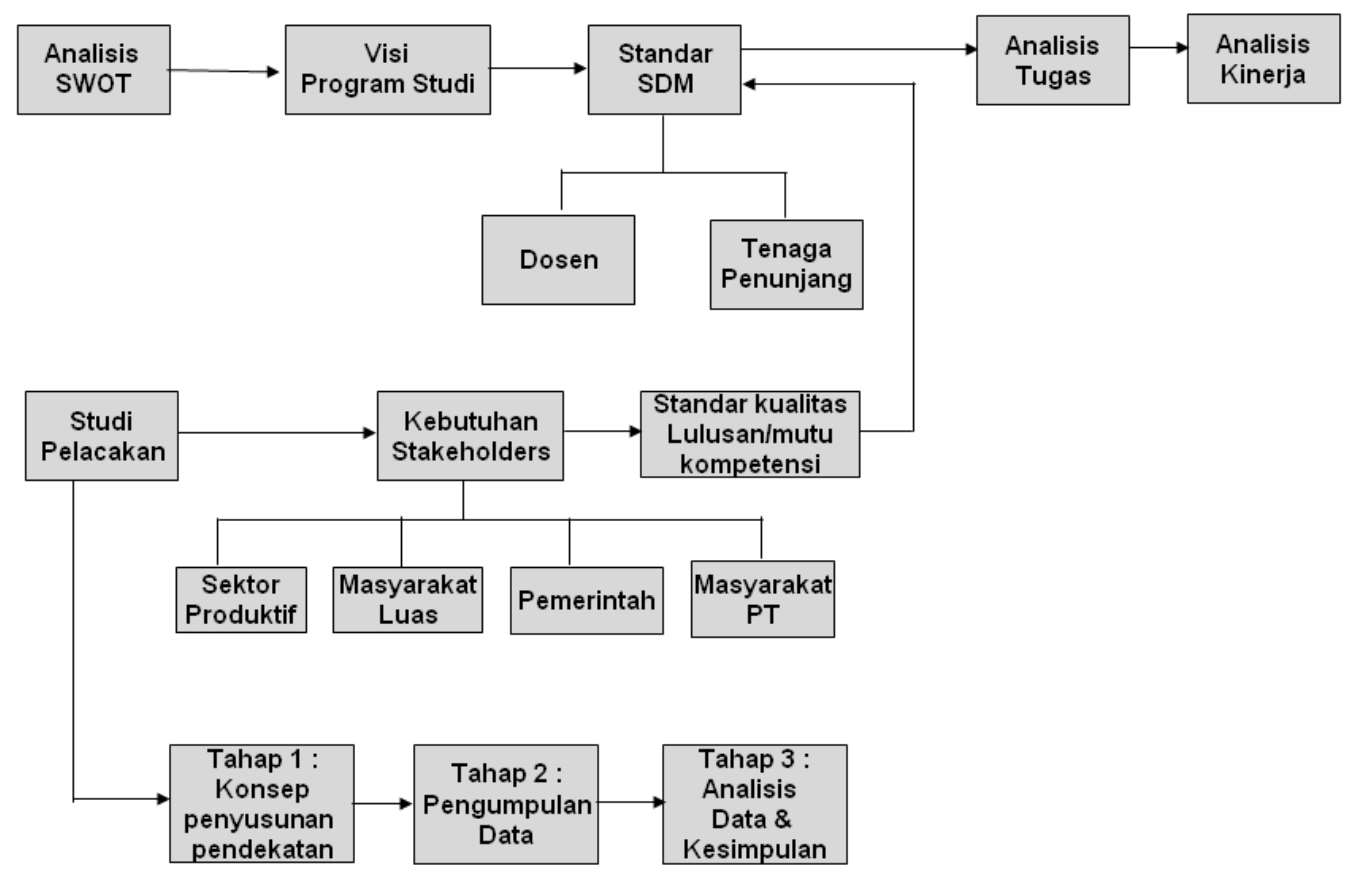

Gambar 2. Mekanisme penetapan standar mutu SDM di perguruan tinggi. 
Pada tahapan perancangan model proses penjaminan mutu internal dan eksternal dibuat model proses untuk penyelenggaraan penjaminan mutu SDM di lingkungan Universitas Paramadina berbasis komputerisasi. Tahapan analisis kebutuhan perangkat lunak dilakukan analisis modul-modul software yang dibutuhkan dalam pembangunan perangkat lunak penjaminan mutu SDM di lingkungan Universitas Paramadina.

Tahapan desain meliputi beberapa kegiatan yang dapat diuraikan antara lain, arsitektur data, arsitektur perangkat lunak, arsitektur tampilan, arsitektur infrastruktur. Arsitektur data yaitu menentukan sumber data apa saja yang dibutuhkan, di mana letaknya dan bagaimana cara mengaksesnya.

Pada arsitektur perangkat lunak ditentukan software yang akan digunakan, apa saja yang akan dibuat menggunakan software tersebut, fungsifungsi yang akan dibuat serta bagaimana menggunakan dan memanggilnya. Pada arsitektur tampilan dilakukan desain tata letak dan tampilan (user interface). Arsitektur infrastruktur menentukan modul aplikasi dan basis data akan diletakkan di server mana, serta platform komputer apa yang akan digunakan. Tahapan perancangan sistem informasi penjaminan mutu perguruan tinggi bidang SDM dapat dilihat pada gambar 3 .

\section{Hasil dan Pembahasan}

Standar mutu SDM di Universitas X mengacu pada standar yang ditetapkan oleh BANPT serta mengacu pada standar mutu internal Universitas $\mathrm{X}$ dan disesuaikan dengan kebutuhan masing-masing program studi. Secara umum elemen-elemen standar mutu SDM yang diacu dapat diuraikan menjadi beberapa bagian. Pertama, kualifikasi akademik, kompetensi (pedagogik, kepribadian, sosial, dan profesional), dan jumlah (rasio dosen mahasiswa dan jabatan akademik) dosen tetap dan tidak tetap (dosen mata kuliah, dosen tamu, dosen luar biasa dan/atau pakar, sesuai dengan kebutuhan) untuk menjamin mutu program akademik.

Kedua, prestasi dosen dalam mendapatkan penghargaan, hibah, pendanaan program dan kegiatan akademik dari tingkat nasional dan internasional; besaran dan proporsi dana penelitian dari sumber institusi sendiri dan luar institusi. Ketiga, reputasi dan keluasan jejaring dosen dalam bidang akademik dan profesi.

Keempat, jumlah, rasio, kualifikasi akademik dan kompetensi tenaga kependidikan (pustakawan, laboran, analis, teknisi, operator, programmer, instruktur, staf administrasi, dan/atau staf pendukung lainnya) untuk menjamin mutu penyelenggaraan program studi.

Kelima, keefektifan sistem seleksi, perekrutan, penempatan, pengembangan, retensi, dan pemberhentian dosen dan tenaga kependidikan untuk menjamin mutu penyelenggaraan program akademik. Keenam, sistem monitoring dan evaluasi, serta rekam jejak kinerja akademik dosen dan kinerja tenaga kependidikan.

Beberapa contoh matriks penilaian mutu SDM di perguruan tinggi berdasarkan standar BAN-PT tahun 2008 dapat dilihat pada tabel I. Mekanisme pencapaian mutu sumber daya manusia dilakukan melalui beberapa tahapan (gambar 4). Tahapan pertama, menetapkan kecukupan SDM yang merupakan rasio antara dosen tetap dan tenaga penunjang dengan mahasiswa di tingkat program studi maupun universitas. Dengan menetapkan rasio ini maka dapat diketahui jumlah dosen dan tenaga penunjang yang diperlukan.

Tahapan kedua, menetapkan kualifikasi dosen dan tenaga penunjang yang diperlukan. Tahapan ketiga, menentukan sistem rekrutmen. Tahapan keempat, merencanakan pengembangan lingkungan kerja yang sehat dan kompetitif. Tahapan kelima, menetapkan program pembinaan dan pengembangan SDM. Tahapan keenam, monitoring dan evaluasi mutu/kinerja SDM. Tahapan ketujuh, menetapkan sistem penghargaan, sanksi dan sistem remunerasi. Tahapan kedelapan, perbaikan dan penyempurnaan mutu SDM.

Model proses penyelenggaraan penjaminan mutu SDM terdiri dari empat tahap yaitu, model proses sistem rekrutmen SDM, model proses monitoring dan evaluasi kinerja SDM, model proses pemberian reward dan punishment, model proses pembinaan dan pengembangan. Model proses sistem rekrutmen SDM. Universitas X selalu meningkatkan standar rekrutmen dosen dan tenaga pendukung agar mampu memberikan daya dukung terhadap ketercapaian misi dan visi universitas. Kebutuhan akan pegawai selalu dievaluasi dengan baik setiap tahun. Proses rekrutmen dilakukan oleh Direktorat HRD. Permintaan pegawai baru dapat dilakukan oleh atasan langsung dengan mengisi formulir permintaan dan mengajukan ke pihak rektorat dan Direktorat HRD. 


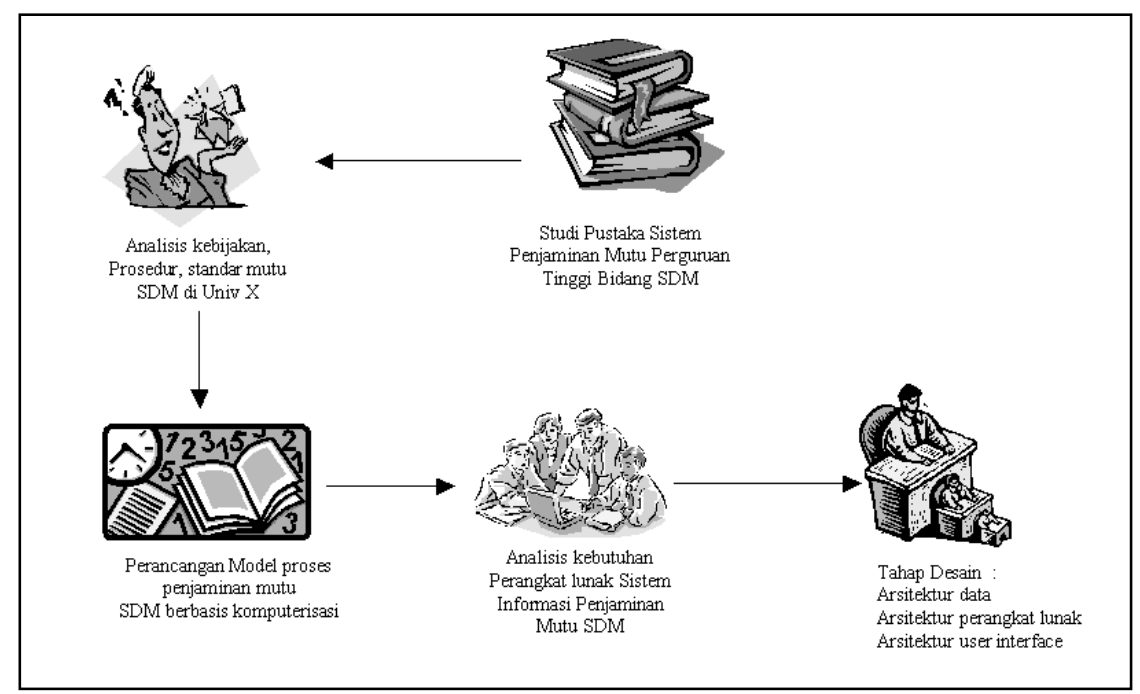

Gambar 3. Tahapan perancangan sistem informasi penjaminan mutu sumber daya manusia.

TABEL I

Matriks Penilaian Mutu SDM Berdasarkan Standar BAN-PT TAHUn 2008

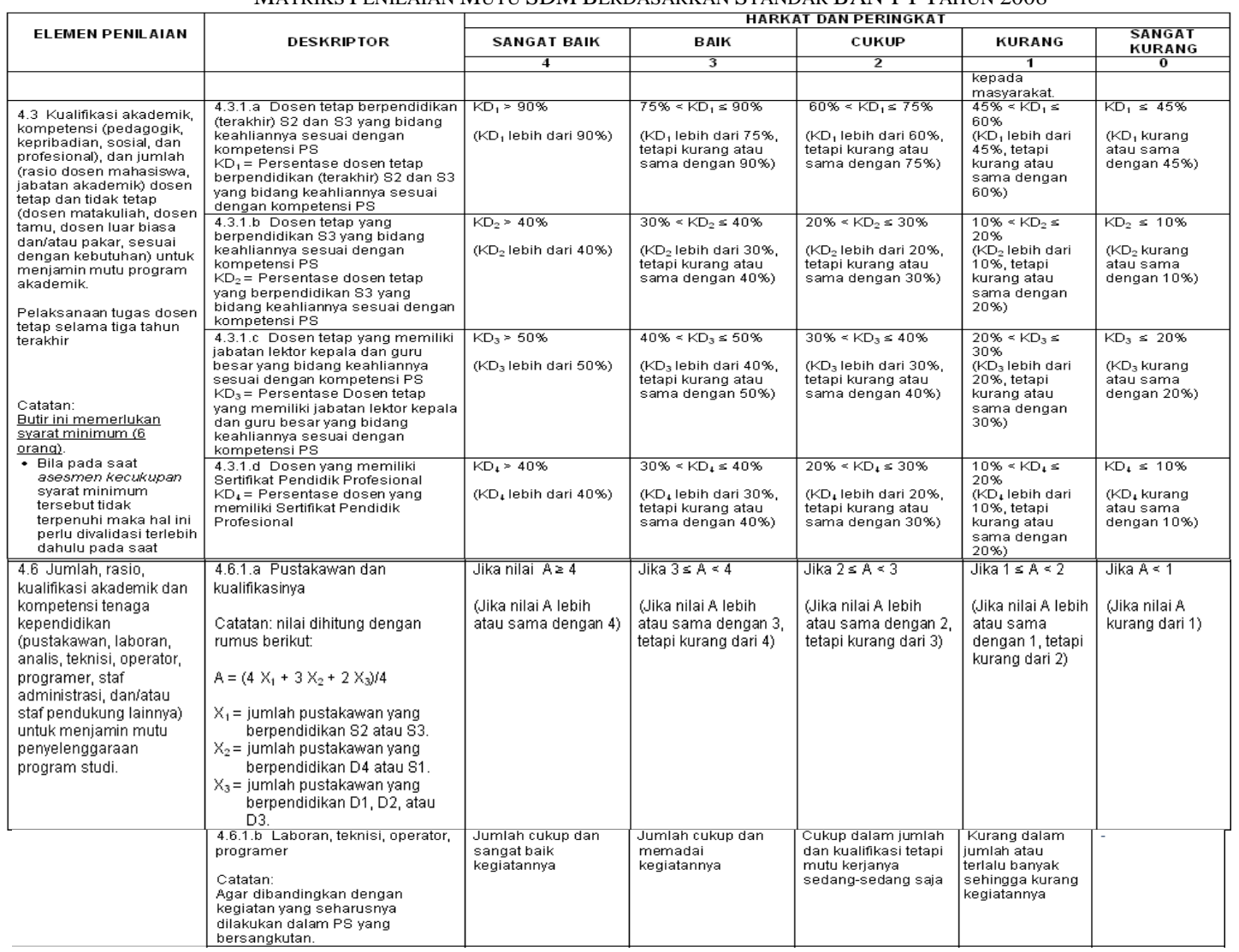

Setelah kebutuhan SDM disetujui oleh pihak rektorat, informasi rekrutmen dan kualifikasi yang dibutuhkan diumumkan melalui media cetak atau situs universitas. Secara umum, beberapa tahapan proses rekrutmen tenaga akademik dan non-akademik dan karyawan Universitas X terdiri dari, wawancara dengan bagian SDM, calon atasan langsung atau ketua jurusan, wawancara/panel di depan rektorat, psikotes yang dilakukan oleh psikolog/lembaga yang ditunjuk. Model proses rekrutment SDM di Universitas X dapat dilihat pada gambar 5 . 


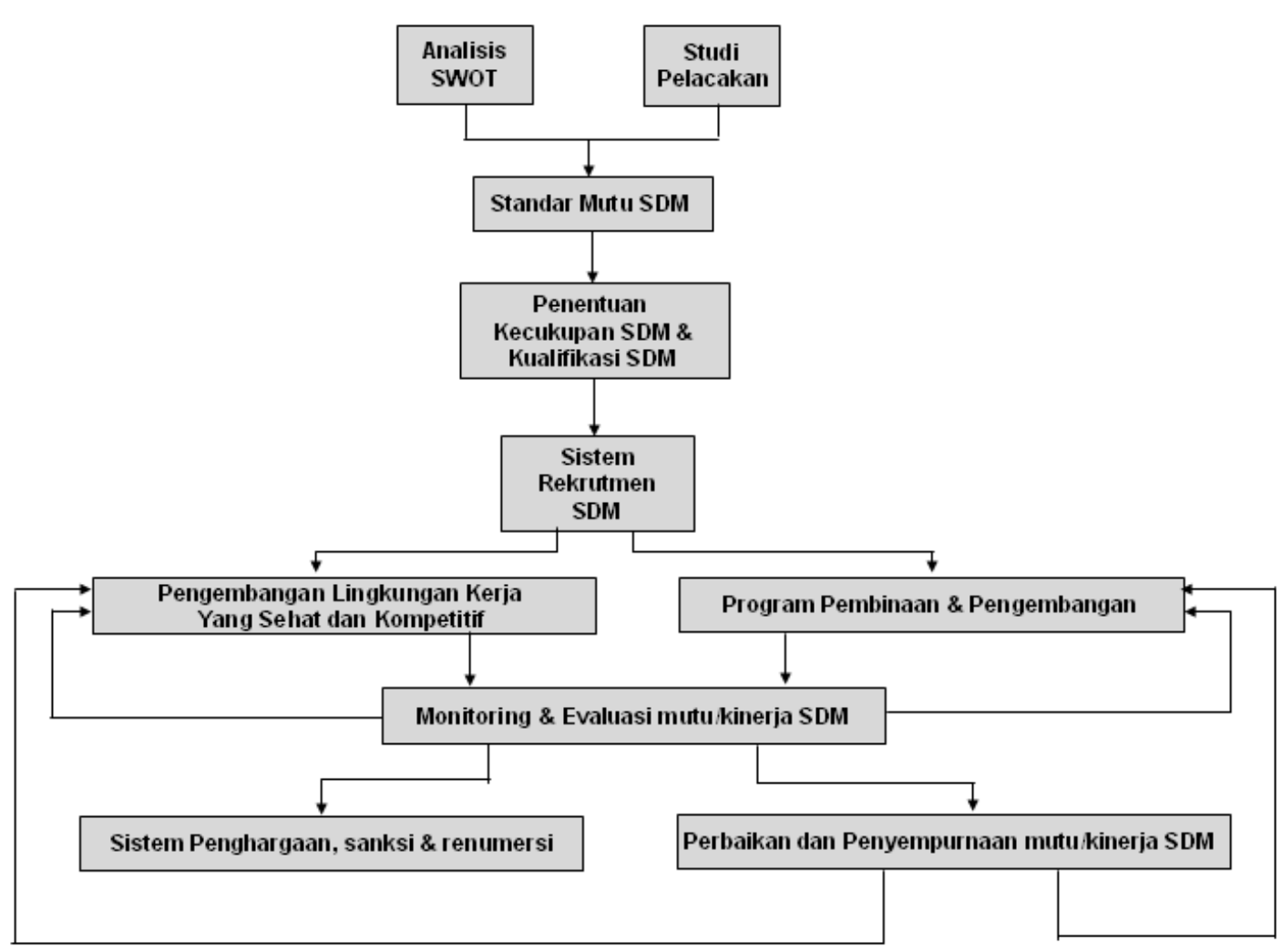

Gambar 4. Mekanisme penjaminan mutu SDM di Universitas X.

Model proses monitoring dan evaluasi kinerja SDM. Monitoring dan evaluasi kinerja SDM adalah proses mengidentifikasi, mengukur, melaporkan, menganalisis dan memberikan feedback atas kinerja SDM selama periode waktu tertentu. Hasil monitoring dan evaluasi kinerja SDM tersebut dapat dijadikan pedoman pelaksanaan kebijakan pemberian reward dan punishment. Di Universitas X monitoring dan evaluasi kinerja SDM dibagi menjadi tiga kelompok yaitu, monitoring dan evaluasi kinerja tenaga pengajar, monitoring dan evaluasi kinerja tenaga administrasi/karyawan, monitoring dan evaluasi kinerja pimpinan. Model proses monitoring dan evaluasi kinerja SDM dapat dilihat pada gambar 6.

Model proses pemberianrReward dan punishment. Universitas $\mathrm{X}$ memiliki sistem pemberian penghargaan dan sanksi serta remunerasi terhadap SDM. Setiap tenaga akademis maupun non akademis harus memperoleh imbalan yang pantas atas tugas yang telah dilakukannya sesuai dengan beban tugasnya masing-masing. Sebaliknya dia juga harus diberitahukan tentang sanksi yang akan diterimanya apabila tidak melaksanakan tugasnya dengan baik. Model proses pemberian reward dan punishment dapat dilihat pada gambar 7.

Model proses pembinaan dan pengembangan. Universitas $X$ memiliki komitmen yang tinggi terhadap proses pembinaan dan pengembangan SDM. Dosendosen didorong untuk melanjutkan pendidikan, melakukan penelitian dan penulisan karya ilmiah, demikian pula tenaga pendukung didorong untuk terus mengembangkan keahlian dan profesionalisme di bidangnya masingmasing melalui kegiatan-kegiatan yang berupa pendidikan formal, pelatihan dan lain-lain. Model proses pembinaan dan pengembangan dapat dilihat pada gambar 8 .

Modul perangkat lunak sistem informasi penjaminan mutu SDM di perguruan tinggi. Berdasarkan desain model proses di atas maka diperlukan beberapa modul aplikasi. Modul yang pertama adalah aplikasi rekrutmen SDM yang digunakan untuk menyimpan data standar, prosedur, kebijakan proses rekrutmen, data kebutuhan SDM, informasi lowongan pekerjaan, data-data pelamar, hasil proses seleksi, dan laporan proses rekrutmen SDM untuk BAN-PT. 


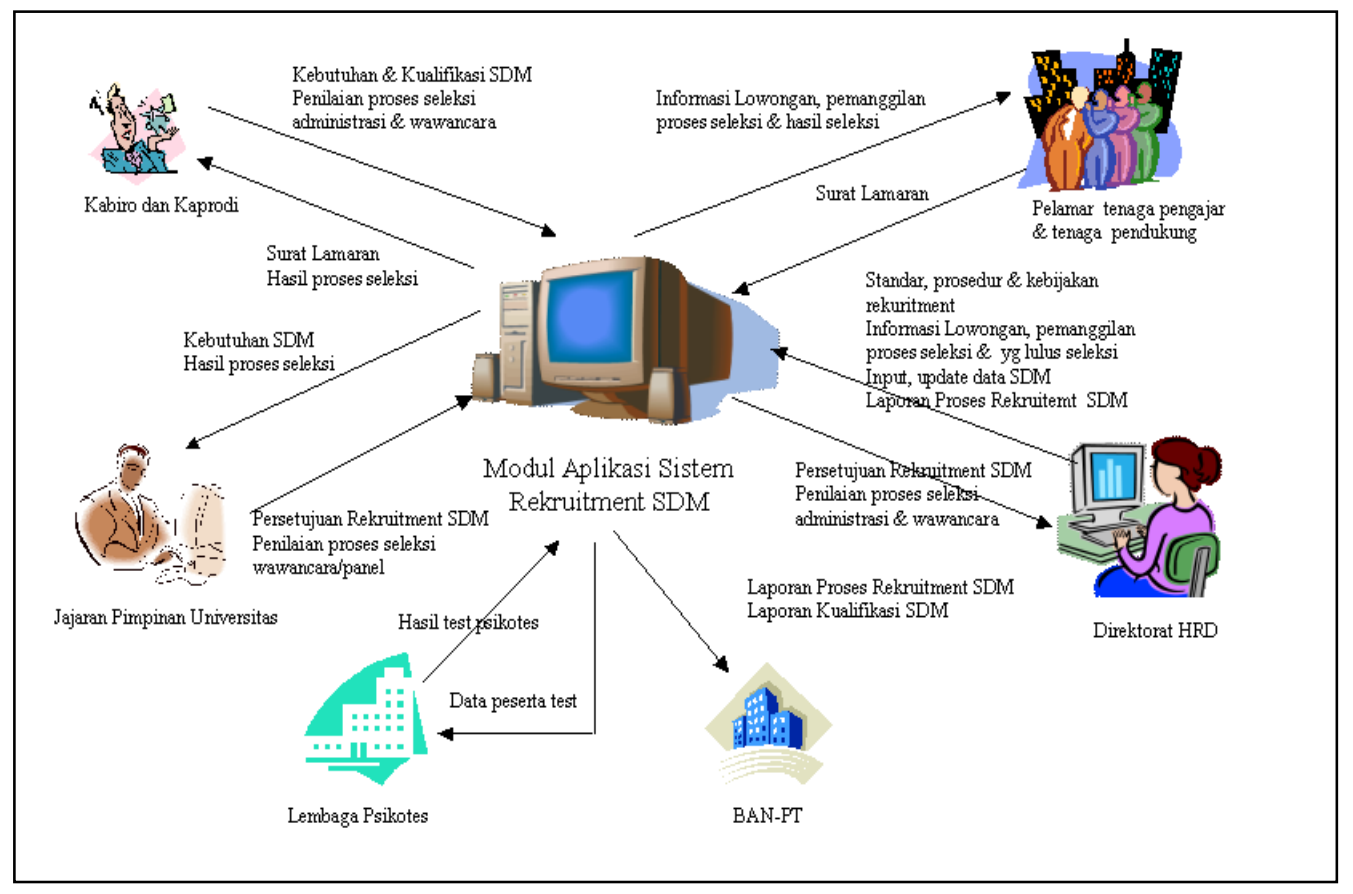

Gambar 5. Model proses rekrutmen SDM di Universitas X.

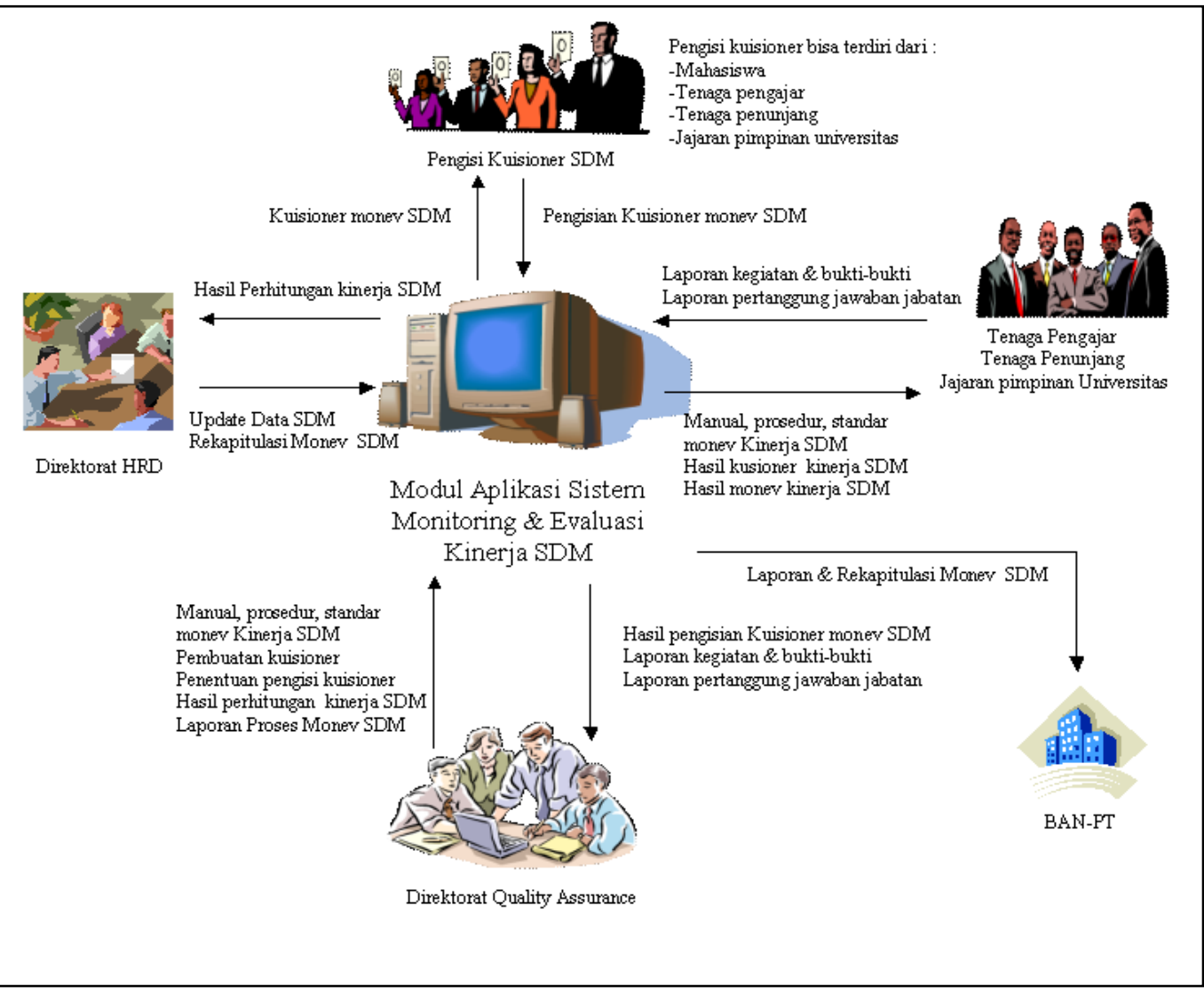

Gambar 6. Model proses monitoring dan evaluasi kinerja SDM di Universitas X. 


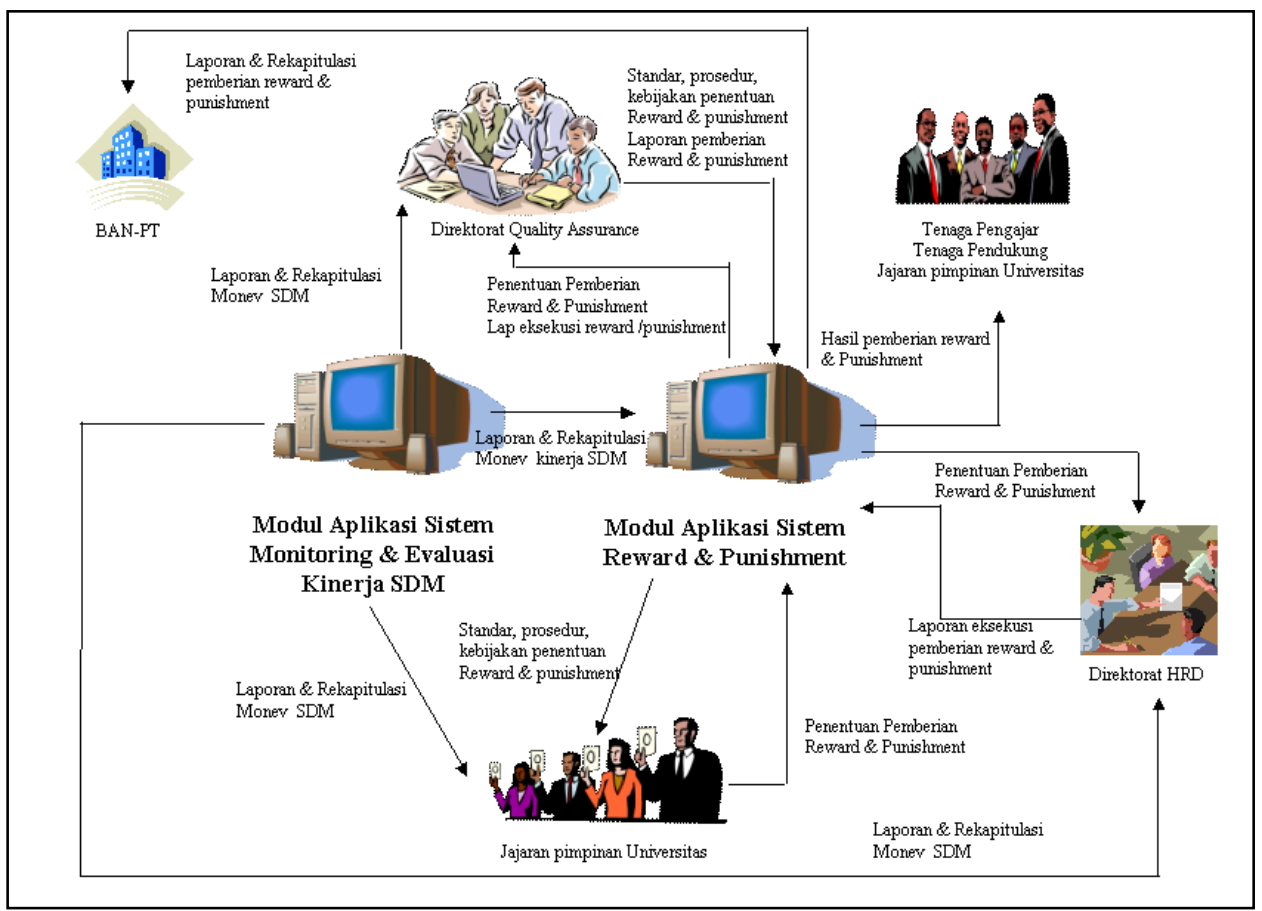

Gambar 7. Model proses pemberian reward dan punishment di Universitas X.

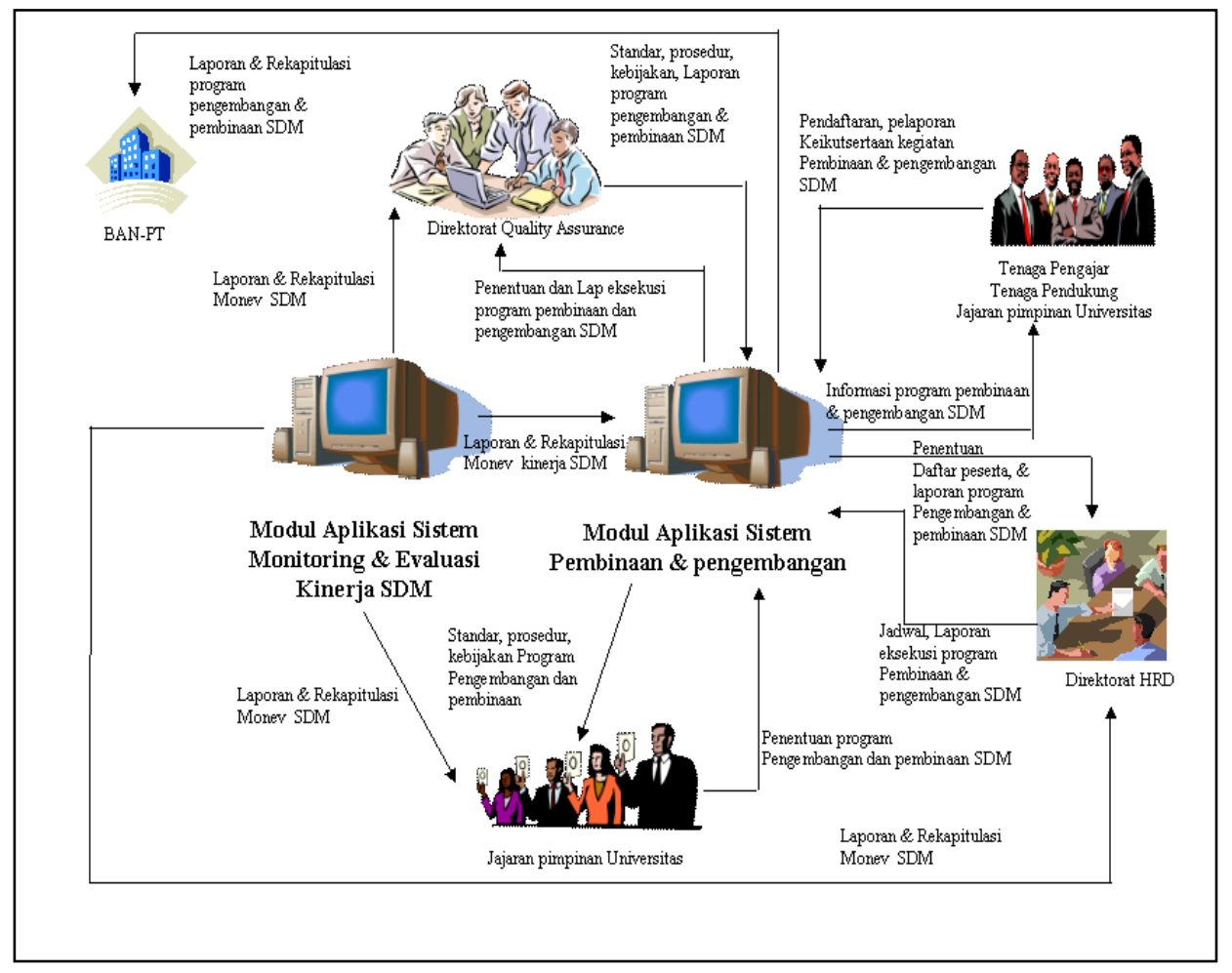

Gambar 8. Model proses pembinaan dan pengembangan SDM di Universitas X.

Modul kedua, aplikasi monitoring dan evaluasi kinerja SDM berisi informasi kegiatan yang telah dilaksanakan oleh dosen dan tenaga pendukung, laporan pertanggungjawaban pelaksanaan jabatan untuk jajaran pimpinan universitas, kuesioner yang harus diisi oleh mahasiswa, teman sejawat dan atasan yang dipilih, aplikasi untuk menghitung skor kinerja 
SDM, laporan proses monitoring dan evaluasi kinerja SDM untuk BAN-PT.Modul ketiga, aplikasi pemberian reward dan punishment berisi data pemberian reward dan punishment kepada SDM berdasarkan skor kinerja yang diperolehnya dan laporan proses pemberian reward dan punishment untuk BAN-PT. Modul keempat, aplikasi pembinaan dan pengembangan SDM berupa data-data kegiatan pembinaan dan pengembangan SDM yang telah dan akan dilaksanakan berdasarkan hasil monitoring dan evaluasi kinerja SDM, laporan proses pembinaan dan pengembangan SDM untuk BAN-PT.

Hasil perancangan proses dan perancangan database sistem informasi penjaminan mutu SDM di perguruan tinggi digambarkan dalam context diagram dan Entity Relationship Diagram (ERD). Penggambarannya dapat dilihat pada gambar 9 dan gambar 10. Beberapa contoh user interface dari aplikasi sistem informasi penjaminan mutu perguruan tinggi bidang SDM di Universitas X dapat dilihat pada gambar 11.

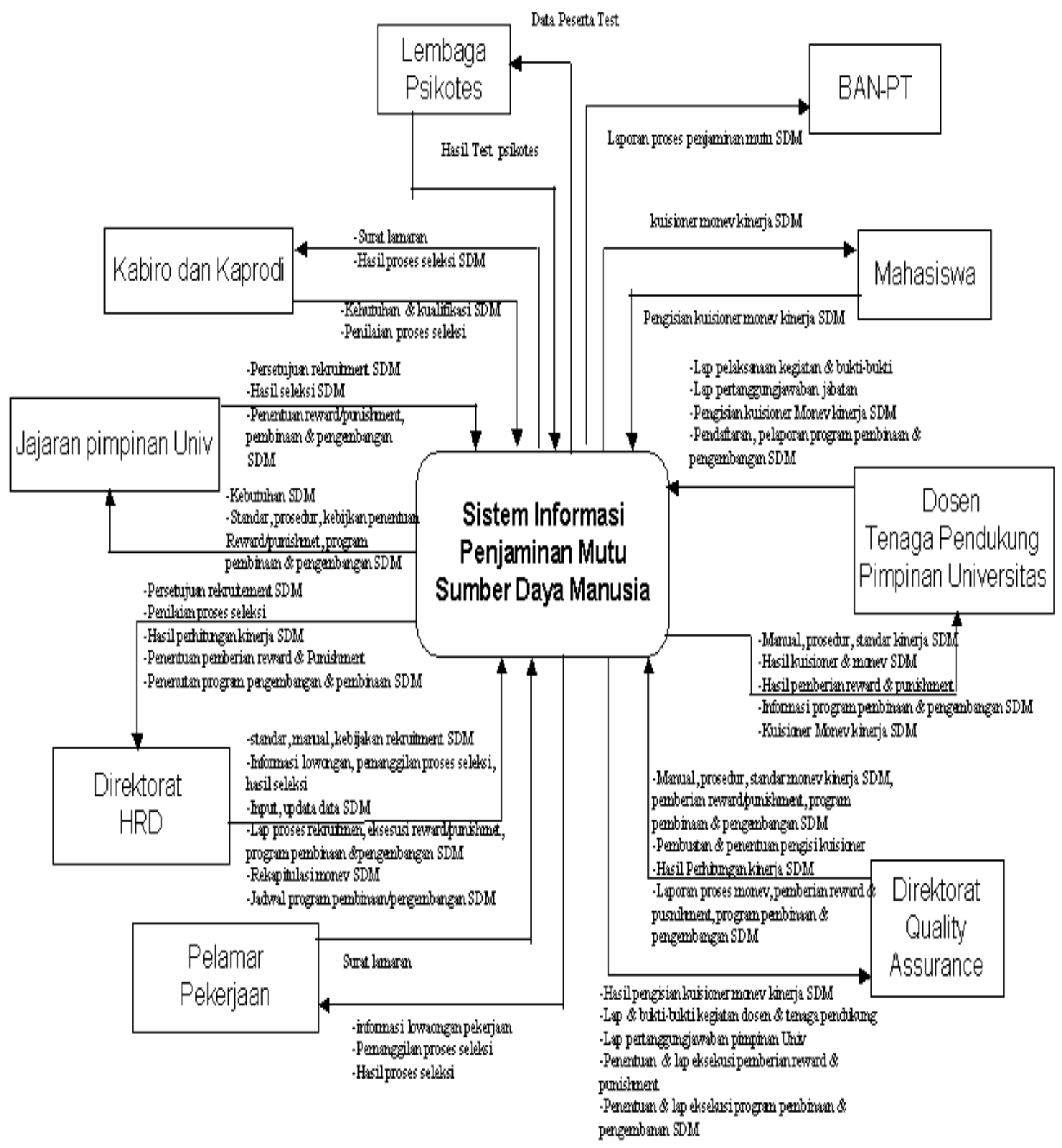

Gambar 9. Context diagram penyelenggaraan penjaminan mutu SDM di perguruan tinggi. 


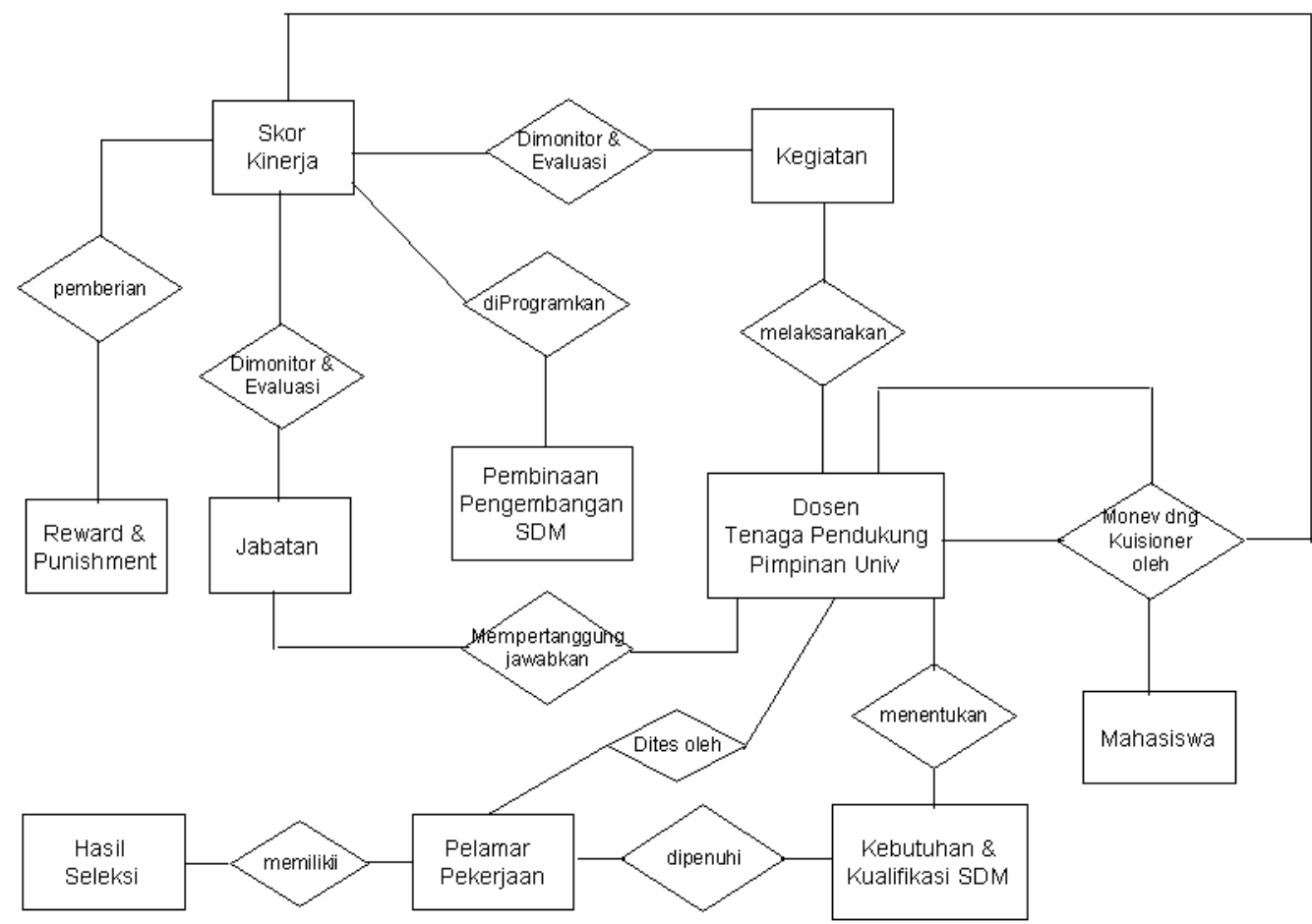

Gambar 10. ERD penyelenggaraan penjaminan mutu SDM di perguruan tinggi.
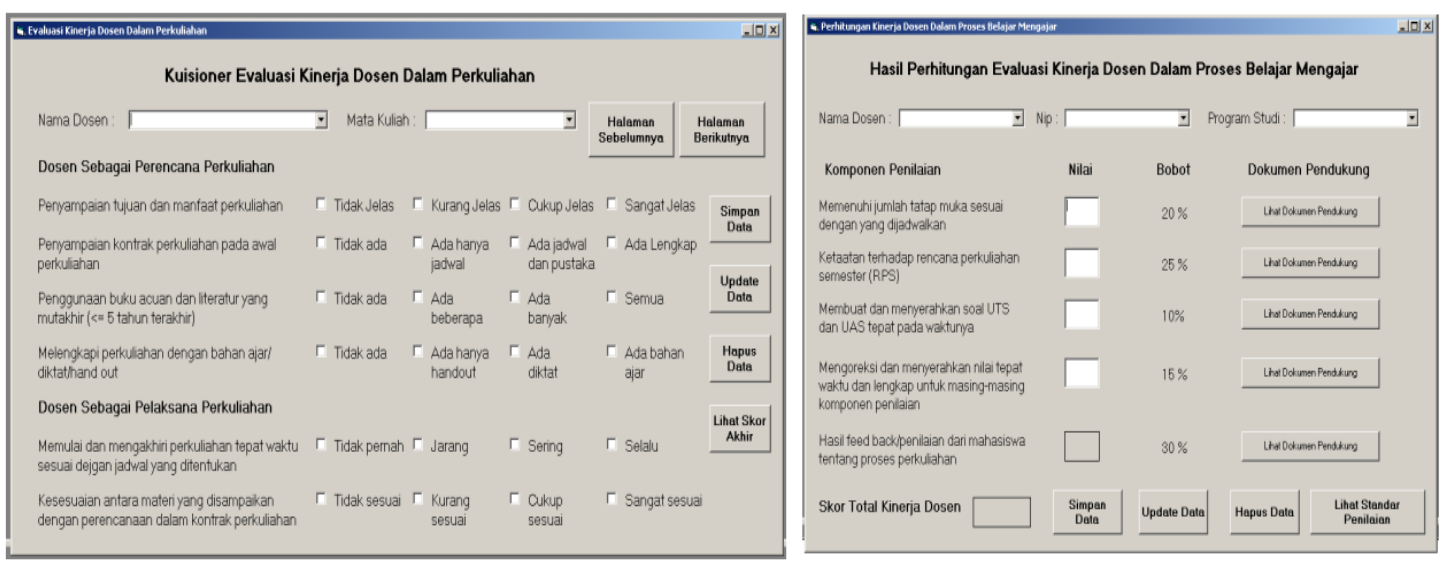

(a)

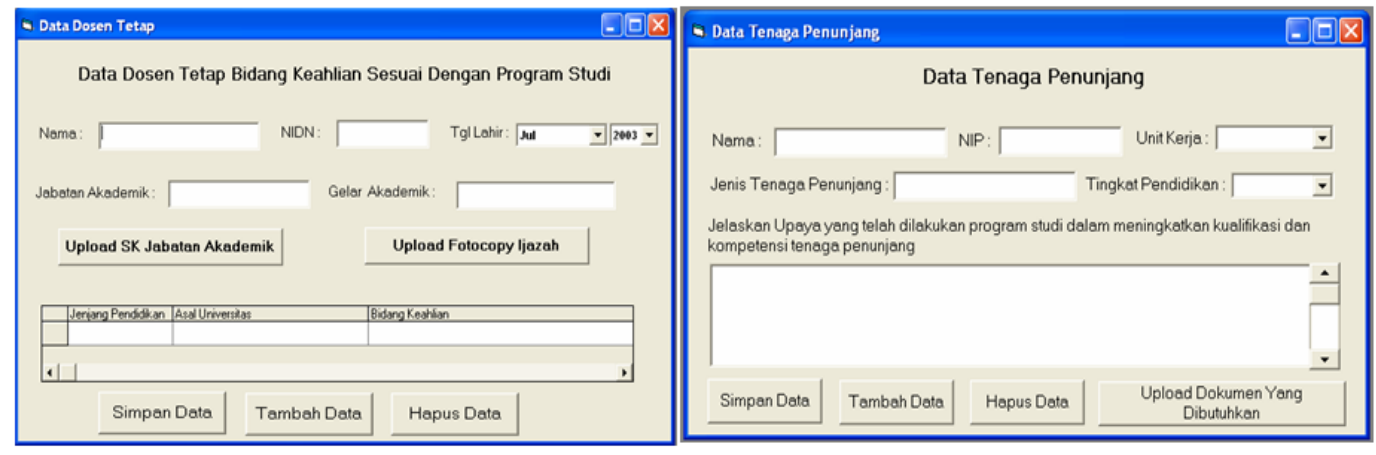

(b) 


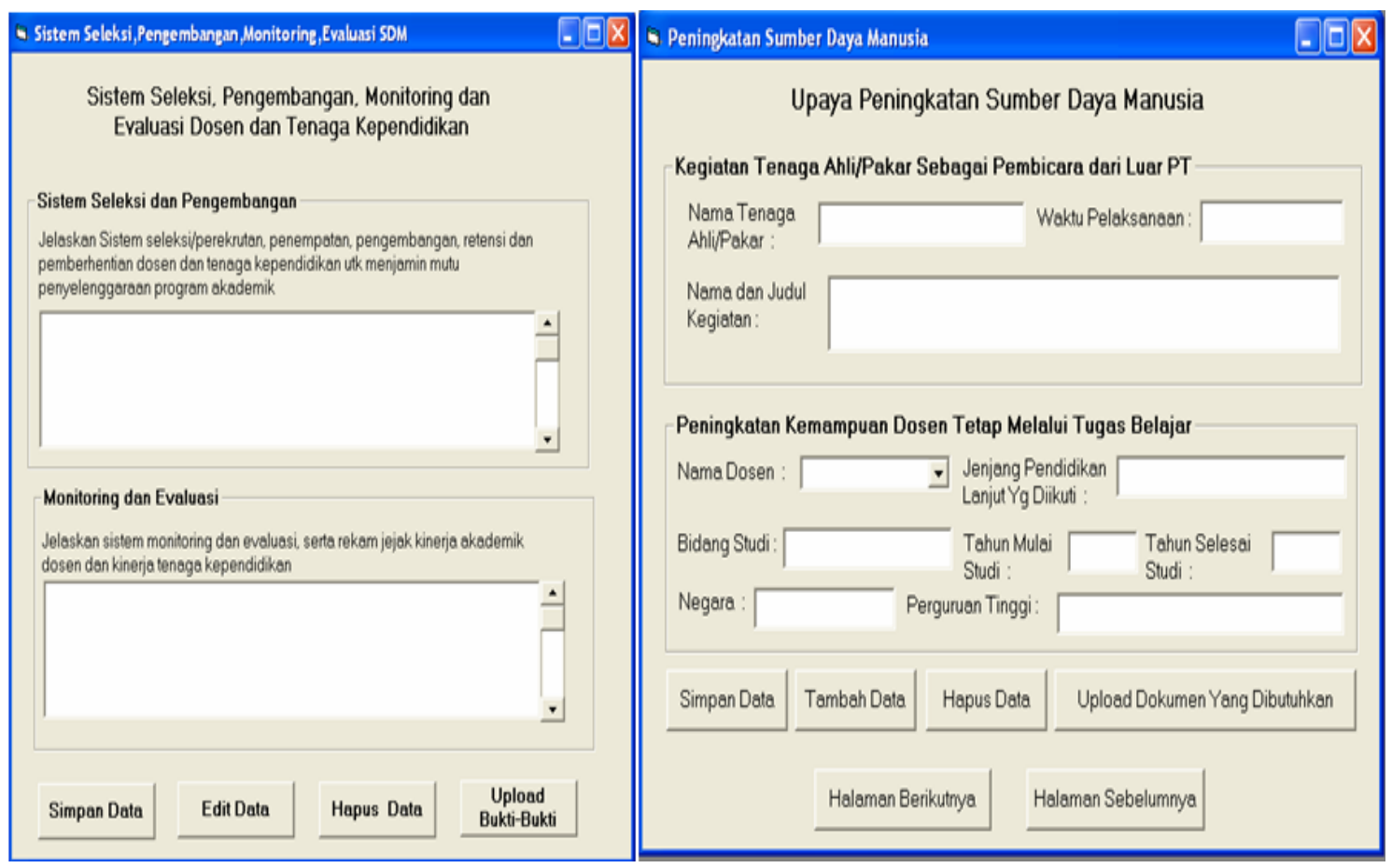

(c)

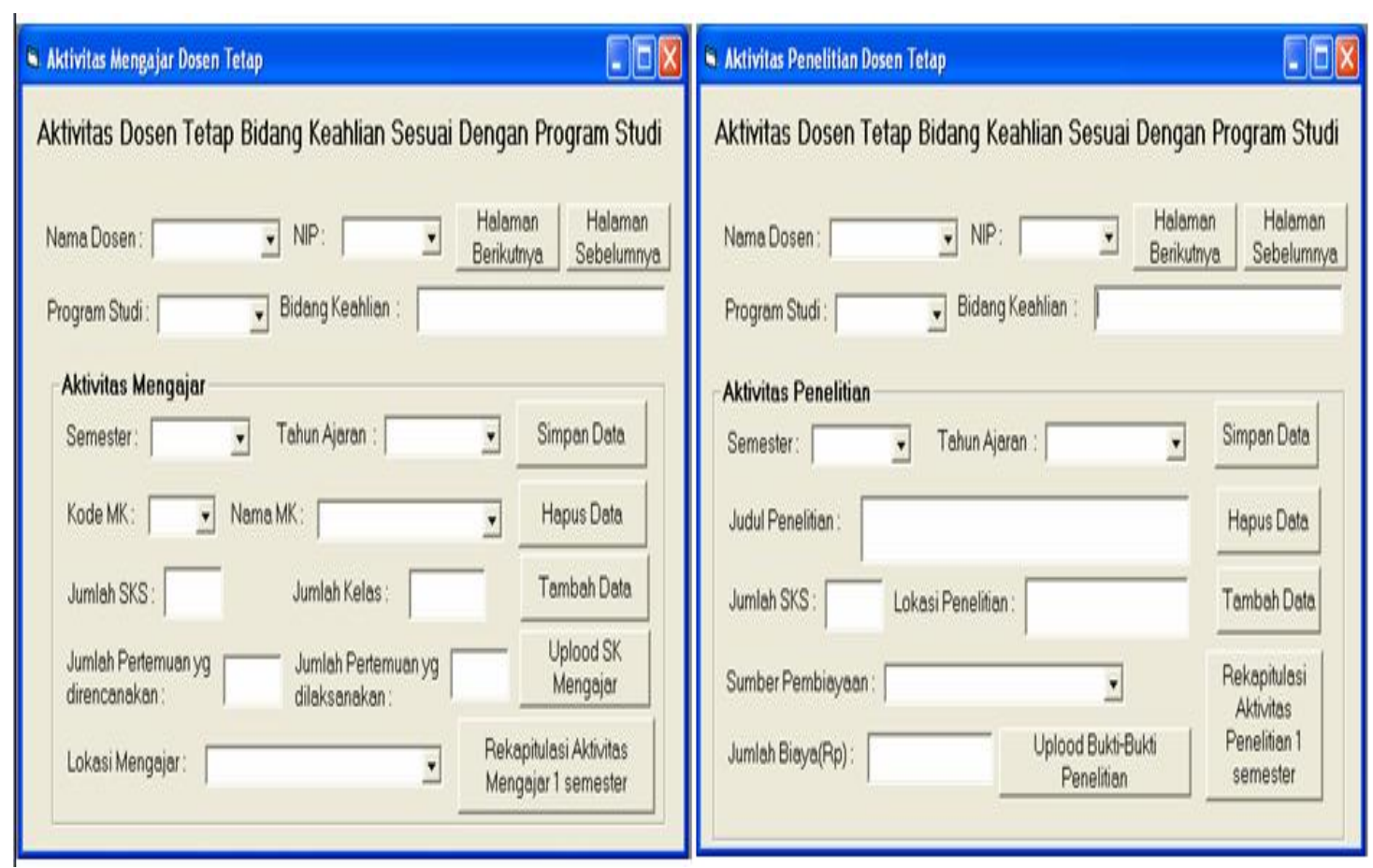

(d)

Gambar 11. User interface aplikasi penjaminan mutu sumber daya manusia. 


\section{Kesimpulan}

Dengan memanfaatkan sistem informasi berbasis komputer, memungkinkan bagi Universitas $\mathrm{X}$ untuk menjalankan penjaminan mutu sumber daya manusia secara konsisten dan berkelanjutan di mana diharapkan dapat meningkatkan kesehatan organisasi sehingga dapat tercipta proses pembelajaran yang kondusif, pengembangan ilmu pengetahuan, teknologi, seni serta meningkatnya kinerja pengelolaan institusi yang akan berdampak pada meningkatnya peringkat mutu Universitas $\mathrm{X}$ di lingkungan nasional maupun internasional. Pada akhirnya keberhasilan penjaminan mutu sumber daya manusia ini juga dapat berimplikasi untuk meningkatkan daya saing Universitas $\mathrm{X}$ di lingkungan global serta dapat berkontribusi langsung pada industri nasional selanjutnya dan dapat berkembang menjadi industri global yang handal serta berkontribusi pada peningkatan daya saing bangsa.

\section{Referensi}

[1] Departemen Pendidikan Nasional, Badan Akreditasi Nasional Perguruan Tinggi, Buku I. Naskah Akademik Akreditasi Program Studi Sarjana, Jakarta, 2008.

[2] Departemen Pendidikan Nasional, Badan Akreditasi Nasional Perguruan Tinggi, Buku II. Standar dan Prosedur Akreditasi
Program Studi Sarjana, Jakarta, 2008.

[3] Departemen Pendidikan Nasional, Badan Akreditasi Nasional Perguruan Tinggi, Buku IIIA. Borang Program Studi, Jakarta, 2008.

[4] Departemen Pendidikan Nasional, Badan Akreditasi Nasional Perguruan Tinggi, Buku IV. Panduan Pengisian Borang Akreditasi, Jakarta, 2008.

[5] Departemen Pendidikan Nasional, Badan Akreditasi Nasional Perguruan Tinggi, Buku V. Pedoman Penilaian Instrumen Akreditasi Program Studi Sarjana, Jakarta, 2008.

[6] Departemen Pendidikan Nasional, Badan Akreditasi Nasional Perguruan Tinggi, Buku VI. Matriks Penilaian Instrumen Akreditasi Program Studi Sarjana, Jakarta, 2008.

[7] Departemen Pendidikan Nasional, Direktorat Jenderal Pendidikan Tinggi, Direktorat Pembinaan Akademik dan Kemahasiswaan, Praktek Baik Dalam Penjaminan Mutu Pendidikan Tinggi Buku III Sumber Daya Manusia (Dosen dan Tenaga Penunjang), Jakarta, 2005

[8] R. Pressman, Software Engineering: A Practitioner's Approach, McGraw-Hill Companies, Inc, New York, 2007.

[9] M. Sadeli, Aplikasi Database Visual Basic 6.0 untuk orang Awam, Maxikom, Palembang, 2008.

[10] Badan Penjaminan Mutu Universitas Indonesia, Pendoman Penjaminan Mutu Akademik UI Dosen, Universitas Indonesia, Depok 2007 